\title{
KARAKTERISTIKE MEDONOSNE PČELE (Apis mellifera L.) NA PODRUČJU UNSKO-SANSKOG KANTONA
}

\author{
Characteristics of honey bee (Apis mellifera L.) in the location of \\ Una-Sana Canton
}

\author{
Sadbera Trožić - Borovac ${ }^{1}$, Škrijelj Rifat $^{1}$, Sulejman Alijagić ${ }^{1}$
}

\begin{abstract}
The paper presents the results of measuring the length of proboscis, the cubital index of honey bee Apis mellifera $\mathrm{L}$. and the interview made with the owners of six apiaries located in the Una-Sana Canton. The chosen parameters are relevant for determination of the subspecies of the honey bee that are located in this area, which was the ultimate goal of the study. Based on the results of the length of proboscis which ranges from 6,30 to $7,00 \mathrm{~mm}$, with the average length of $6,56 \mathrm{~mm}$, it was determined that this is a Carniolan honey bee, Apis mellifera carnica (Pollman, 1879). The values of the cubital index ranged between 2, 20 and 3,00 $\mathrm{mm}$, with the average of 2, $63 \mathrm{~mm}$ which is also a characteristic of the Carniolan honey bee.

The work results confirm inhomogeneous genetic system of the bees located in the six analyzed apiaries in the Una-Sana Canton, due to diverse origin of the honey bee queens, taken as genetic material. General ecological conditions such as climate and vegetation, however, shall in the future provide a promising perspective in the development of beekeeping in this area which would impose on import control of the queen bees and thus restrain the outbreak of diseases which are not yet present in this area. By comparing the results given in this paper with the results of those from the Sarajevo Canton, it is notable that the genetic material from the Una-Sana Canton is less inhomogeneous.
\end{abstract}

Key words: honey bee, cubital index, genetic material, queen bee, Carniolan honey bee, proboscis

\section{Izvod}

Rad je prikaz rezultata mjerenja dužine rilice, kubitalnog indeksa kod medonosne pčele Apis melifera L. i intervjua sa vlasnicima šest pčelinjaka Unsko-sanskog kantona. Odabrani parametri su relevantni za utvrđivanje podvrste ili pasmine medonosne pčele koja se uzgaja na ovom području, a to je ujedno i cilj rada. Na osnovu rezultata dužine rilice koja se kreće u intervalu od 6,30 do 7,00 mm, sa prosječnom dužinom od 6,56 mm,

\footnotetext{
${ }^{1}$ Prirodno-matematički fakultet Univerziteta u Sarajevu
} 
zaključuje se da je ovo kranjska pčela Apis mellifera carnica (POLLMAN, 1879). Vrijednosti kubitalnog indeksa kreću se u intervalu od 2,20 do 3,00 mm, sa prosjekom od 2,63 mm što je takođe svojstveno kranjskoj pčeli.

Uslijed različitog porijekla matica, kao nasadnog materijala, rezultat je nehomogen genetski sastav pčela koje se uzgajaju na šest analiziranih pčelinjaka na području Unsko-sanskog kantona. Opći ekološki uvjeti (klima, vegetacija) u budućnosti će omogućavati prespektivan razvoj pčelarstva na ovom području. Ono bi zahtijevalo kontrolu unosa matica radi sprečavanja zaraznih oboljenja koja još nisu prisutna na ovom prostoru. Upoređujući rezultate dobivene u ovom radu sa rezultatima dobivenim na prostoru Kantona Sarajevo, zapaže se da je nasadni materijal sa Unskosanskog kantona manje nehomogen.

Ključne riječi: medonosna pčela, kubitalni indeks, genetski materijal, matica, kranjska pčela

\section{UVOD - Introduction}

Medonosna pčela Apis mellifera L. u svom je evolutivnom razvoju promjenivši uvjete života u odnosu na solitarne (usamljene) pčele te prave ose, otišla drugim evolutivnim putem, tako da se danas po svom načinu života, građi i obliku tijela znatno razlikuje od svojih predaka. Veoma značajan faktor koji je vodio nastanku današnje savremene pčelinje zajednice bila je pojava partenogenetskog razvića, tj. razvića iz neoplođene jajne ćelije (STANIMIROVIĆ I SUR., 2000). Određivanje morfometrijskih krakteristika je matematičko-statistička metoda koja proučava varijabilnost (promjenljivost) između jedinki pčela i koristi se kao pomoćna metoda $u$ izračunavanju srednje vrijednosti određenih parametara i provođenju selekcije. Tehnika rada određivanja morfometrijskih karakteristika prilagođena je određenim specifičnostima svakog karaktera ponaosob. Svi parametri se ne koriste jednako učestalo. Izdvojeni su oni parametri koji se češće koriste a zajedno dovoljno opisuju pasminu (DomINKOVIĆ I SUR., 1997). U Bosni i Hercegovini, kao i na području svih zemalja bivše Jugoslavije, raširena je kranjska medonosna pčela Apis mellifera carnica Polm. Prema podacima prapostojbina ove rase je Indija (DomINIKOVIĆ I SUR., 1994). U svijetu su opisane četiri vrste medonosnih pčela: Apis indica F. - indijska pčela, Apis florea F. - mala indijska pčela, Apis dorsata F. - velika indijska pčela i Apis mellifera L. - evropsko-afrička medonosna pčela. Prapostojbina pčele medarice je tropska Afrika, sjeverna Afrika, sjeverna Evropa, Indija i Kina. Kolonizacijom Amerike pčela medarica se raširila širom svijeta. Najstariji fosilni ostaci pčele medarice datiraju od prije 40 miliona godina iz eocena (KoNING, 1994). Na širem području evropskog kontinenta prostire se medonosna pčela Apis mellifera L. sa više varijeteta, ali su u naučnoj literaturi prihvaćene četiri ekonomski značajne rase pčela, i to: Apis mellifera mellifera L. - tamna holandsko-njemačka medonosna pčela, Apis mellifera caucasica Gorb. - kavkaska (tamna i žuta) medonosna pčela, Apis mellifera ligustica Spin - italijanska (žuta) medonosna pčela, Apis mellifera carnica Polm. kranjska (siva) medonosna pčela. Apis mellifera mellifera Linné 1758 tamna je 
medonosna pčela koja naseljava prostor sjeverne i srednje Evrope, a najviše je ima u Holandiji, Njemačkoj, Francuskoj i skandinavskim zemljama.

O porijeklu medonosne pčele na prostorima Bosne i Hercegovine postoji malo pouzdanih podataka, bilo pisanih bilo paleontoloških nalaza koji govore o njenom porijeklu i evolutivnom razvoju. Pisani tragovi sežu iz druge polovine XVIII stoljeća i govore o kranjskoj medonosnoj pčeli Apis mellifera L. koja se adaptirala na životne uvjete naših prostora. Po prirodnim resursima, naša zemlja spada u red prirodno bogatih zemalja i vrlo povoljnih za pčelarenje.

Procijenjuje se da je devedesetih godina prošlog stoljeća u Bosni i Hercegovini postojalo 150 hiljada pčelinjih društava, a da se pčelarstvom bavila 31 hiljada domaćinstava. Tokom rata uništeno je $70 \%$ od ukupnog broja društava. Uslijed velikog značaja razvoja ove grane privrede, a s obzirom na stupanj razorenosti prostora naše države, ova grana privrede umnogome treba da predstavlja jedan od načina ekonomskog prosperiteta kako pojedinca tako i države uopće.

$\mathrm{Na}$ našim prostorima ljudi se bave pčelarstvom uglavnom radi meda i voska. U zapadnoevropskim zemljama države daju podsticaje pčelarima da drže pčele $u$ blizini poljoprivrednih parcela, pogotovo nekih krmnih biljaka, jer su naučno dokazani veći prinosi npr. suncokreta, uljane repice i drugih biljnih vrsta tamo gdje su u blizini bili pčelinjaci. Na drugom mjuestu po važnosti je med. Dakle, dokazana je simbioza između pčela i velikog broja biljnih vrsta, odnosno veća je indirektna korist pčela kao oprašivača biljaka od direktne koristi meda kojeg daju preradom nektara za oko 100 do 150 puta (ĆERIMAGIĆ, SAVIĆ, 1991), jer u prirodi oko $80 \%$ biljaka su entomofilne (biljke koje oprašuju insekti). Na prostoru Unsko-sanskog kantona je registrovano oko 14.000 pčelinjih društava sa tendencijom stalnog rasta. U Bosni i Hercegovini posljednjih godina obnovljen je prijeratni broj pčelinjih društava što umnogome ukazuje na perspektive razvoja ove značajne grane privrede, kao ekološki čiste i po čovjekovu životnu okolinu zdrave privredne grane.

Prema analizi značaja porijekla medonosne pčele na prostorima Bosne i Hercegovine, tendenciji razvoja pčelarstva kao posebne grane privrede, pristupilo se po prvi put analizi nekih najznačajnijih morfometrijskih parametara medonosne pčele na području Unsko-sanskog kantona. Cilj analize izmjerenih vrijednosti morfo-metrijskih parametara (kubitalni indeks, dužina rilice) kod jedinki pčela radilica i determinacija rase koja se uzgaja, je utvrđivanje čistoće genskog sastava uzgajane vrste pčele medarice i sagledavanje uticaja vanjskih faktora na neke morfometrijske karaktere. Imjerene vrijednosti su komparirarane sa sličnim istraživanjima u Bosni i Hercegovini (POTURAK, 2000), te naznačene preporuke za intenzivniji razvoj pčelarstva na području Unsko-sanskog kantona i prostora Bosne i Hercegovine uopće.

\section{METODE RADA - Work methods}

U radu su korištene žive pčele, po 100 jedinki iz šest pčelinjaka Unsko-sanskog kantona: Bosanska Krupa (lok.br.1), Sanski Most (lok.br.2), Bosanski Petrovac (lok.br.3), Bihać (lok.br.4), Cazin (lok.br.5) i Velika Kladuša (lok.br.6), uzetih u periodu septembar - 
oktobar 2004. godine. Obrada i mjerenje parametara na radilicama pčele medarice iz pčelinjaka Unsko-sanskog kantona vršeni su u laboratoriju Odsjeka za biologiju Prirodnomatematičkog fakulteta Sarajevo, u periodu od septembra do decembra 2004. godine. Od morfometrijskih parametara izvršena su sljedeća mjerenja:

\section{a) Dužina rilice}

Za mjerenje dužine rilice izvršena je disekcija usnog aparata kod 50 jedinki radilica, pri čemu je korišten standardni pribor za disekciju nakon čega su rilice fiksirane između dva predmetna stakla kanada balzamom i napravljeni trajni preparati. Nakon sušenja preparata, uz pomoć binokularne lupe tipa Eschenbach sa uvećanjem WF 10X i uz pomoć milimetarskog papira, izvršeno je mjerenje dužine rilice. Izmjerene vrijednosti su prikazane tabelarno.

\section{b) Kubitalni indeks}

Za mjerenje odnosa stranica a i b treće kubitalne stanice na prednjem krilu pčele radilice (sl. 2) korištena je 100 jedinki (Ruttner, 1988). Krila su fiksirana kanada balzamom između dva predmetna stakla i napravljeni su trajni preparati. Mjerenje je izvršeno korištenjem milimetarskog papira i binokularne lupe. Dobivene vrijednosti za svaki pčelinjak predstavljene su tabelarno i grafički.

\section{c) Intervju sa vlasnicima pčelinjaka}

Sa vlasnicima pčelinjaka je prilikom uzimanja uzoraka pčela za mjerenje navedenih morfometrijskih karaktera obavljen i kratki razgovor (intervju). Pri razgovoru sa vlasnicima pčelinjaka iz kojih su uzimani uzorci pčela vodilo se računa o dobijanju informacija o porijeklu pčelinje zajednice te posebno o biološkim karakteristikama i karakteristikama ponašanja pčela, tj. o sljedećem:

$\Rightarrow$ preživljavanje pčela,

$\Rightarrow \quad$ kako pčele prezimljuju zimu,

$\Rightarrow \quad$ količina legla i broj pčela tokom glavne pčelinje ispaše,

$\Rightarrow \quad$ kakav je nagon za rojenje,

$\Rightarrow \quad$ mirnoća pčela na saću,

$\Rightarrow \quad$ sklonost ka grabežu,

$\Rightarrow \quad$ sklonost ka sakupljanju polena i propolisa,

$\Rightarrow \quad$ osjećaj pčela za orijentacijom (ima li zalijetanja u tuđe košnice) i druga pitanja.

\section{REZULTATI ISTRAŽIVANJA - The results of the study}

U okviru analize morfometrijskih karakteristika pčele medarice na šest lokaliteta (pčelinjaka) Unsko-sanskog kantona dobiveni su rezultati za sve morfometrijske karaktere analizirane u ovom radu: 
- dužina rilice

- $\quad$ kubitalni indeks

Rezultati mjerenja kubitalnog indeksa i dužine rilice razmatrani su odvojeno kao zbirni prikaz radi lakše uporedbe na različitim pčelinacima, a odvojeno je prikazan intervju sa vlasnicima pčelinaka. Prikazani rezultati su komparirani sa rezultatima morfometrisjskih mjerenja pčele medarice u pčelinacima sa područja Kantona Sarajevo (POTURAK, 2000).

\section{- Analiza dužine rilice svih 300 uzoraka sa Unsko-sanskog kantona}

Na lokalitetima šest pčelinjaka na području Unsko-sanskog kantona izvršena su mjerenja dužine rilice kao sastavnog dijela usnog aparata za lizanje i srkanje na 300 jedinki medonosne pčele. Izmjerene vrijednosti svih jedinki kreću se u intervalu od najmanje vrijednosti $6,30 \mathrm{~mm}$ (osam jedinki) do najveće vrijednosti od 7,00 $\mathrm{mm}$ (šest jedinki). Prema izračunatoj srednjoj vrijednosti od $6,56 \mathrm{~mm}$, (tab. 1.) pčelinja društva sa Unsko-sanskog kantona za karakter dužina rilice pripadaju kranjskoj rasi pčela Apis mellifera carnica $\mathrm{P}$.

Tabela 1. Vrijednosti dužine rilice izmjerene kod 300 jedinki radilica medonosne pčele iz šest pčelinjaka sa područja Unsko-sanskog kantona, oktobar 2004. god.

(Table 1. Values of the proboscis length measured from 300 honey bees from 6 apiaries from the location of Una-Sana Canton, October 2004)

\begin{tabular}{|c|c|c|c|c|c|c|c|c|c|c|c|c|}
\hline \multicolumn{13}{|c|}{ DUŽINA RILICE } \\
\hline & zzredi & \begin{tabular}{c|}
6,0 \\
\end{tabular} & $6,6,1$ & $\begin{array}{l}6,2 \\
\end{array}$ & $\begin{array}{c}6,4 \\
\end{array}$ & $\begin{array}{l}6,5 \\
\end{array}$ & $\begin{array}{l}6,6 \\
\end{array}$ & $\begin{array}{c}6,7 \\
\end{array}$ & $\begin{array}{l}\mathbf{6 , 8} \\
\end{array}$ & 6 & $\overline{7,0}$ & \\
\hline \multirow{6}{*}{ 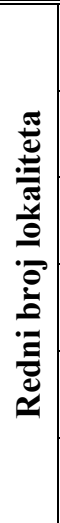 } & $\begin{array}{l}\text { Lok. } \\
\text { br. } 1 .\end{array}$ & & & & 2 & 22 & 14 & 10 & 2 & & & $X=6,58$ \\
\hline & $\begin{array}{l}\text { Lok. } \\
\text { br. } 2 .\end{array}$ & & & & 2 & 13 & 6 & 15 & 9 & & 5 & $X=6,67$ \\
\hline & $\begin{array}{l}\text { Lok. } \\
\text { br. } 3 .\end{array}$ & & & 2 & 5 & 25 & 7 & 8 & 3 & & & $X=6,55$ \\
\hline & $\begin{array}{l}\text { Lok. } \\
\text { br. } 4 .\end{array}$ & & & 2 & 4 & 25 & 10 & 6 & 3 & & & $X=6,55$ \\
\hline & $\begin{array}{l}\text { Lok. } \\
\text { br. } 5 .\end{array}$ & & & 2 & 5 & 15 & 4 & 15 & 9 & & & $X=6,60$ \\
\hline & $\begin{array}{c}\text { Lok. } \\
\text { br. } 6 .\end{array}$ & & & 2 & 1 & 26 & 9 & 7 & 4 & & 1 & $X=6,57$ \\
\hline \multirow{2}{*}{ 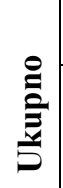 } & & & & 8 & 19 & 126 & 50 & 61 & 30 & & 6 & $\Sigma 300$ \\
\hline & & & & 50,4 & 122 & 819 & 330 & 408.7 & 204 & & 35 & $X=6,57$ \\
\hline
\end{tabular}




\section{- Analiza kubitalnog indeksa (CI) za Unsko-sanski kanton 600 jedinki radilica medonosne pčele}

Kubitalni indeks (CI) izračunat je kod 600 jedinki radilica medonosne pčele sa šest lokaliteta Unsko-sanskog kantona, a dobivene vrijednosti se kreću u intervalu od 2,20 mm (šest jedinki) do 3,00 mm (45 jedinki). Srednja vrijednost kubitalnog indeksa (CI) pčela medearica za Unsko-sanski kanton iznosi 2,63 mm (tab.2), što je odgovarajuće za kranjsku rasu Apis mellifera carnica.

Tabela 2. Vrijednosti kubitalnog indeksa (CI) kod 600 jedinki radilica medonosne pčele sa šest lokaliteta Unsko-sanskog kantona, oktobar 2004. god.

(Table 2. Values of cubital index from 600 honey bees from 6 localities of Una-Sana Canton, October 2004)

\begin{tabular}{|c|c|c|c|c|c|c|c|c|c|c|c|c|}
\hline \multicolumn{13}{|c|}{ KUBITALNI INDEKS } \\
\hline & azredi & 2,20 & 2,30 & 2,40 & 2,50 & 2,60 & 2,7 & 2,80 & 2,9 & 3,00 & 3,10 & \\
\hline \multirow{6}{*}{ 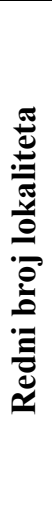 } & $\begin{array}{l}\text { Lok. } \\
\text { br. } 1\end{array}$ & 2 & 8 & 9 & 13 & 23 & & 35 & & 10 & & $X=2,65$ \\
\hline & $\begin{array}{l}\text { Lok. } \\
\text { br. } 2 .\end{array}$ & & 12 & 10 & 30 & & & 42 & & 6 & & $X=2,62$ \\
\hline & \begin{tabular}{|l} 
Lok. \\
br. 3
\end{tabular} & 2 & 8 & 25 & & 40 & & 23 & & 2 & & $X=2,55$ \\
\hline & \begin{tabular}{|l} 
Lok. \\
br. 4. \\
\end{tabular} & 2 & 4 & 11 & 10 & 35 & & 31 & & 7 & & $X=2,62$ \\
\hline & \begin{tabular}{|l} 
Lok. \\
br. 5 \\
\end{tabular} & & 6 & & 18 & 28 & & 38 & & 10 & & $X=2,68$ \\
\hline & \begin{tabular}{|l} 
Lok. \\
br. 6. \\
\end{tabular} & & 4 & 11 & 15 & 33 & & 27 & & 10 & & $X=2,65$ \\
\hline \multirow{2}{*}{$\frac{\frac{a}{\bar{z}}}{\frac{\bar{z}}{5}}$} & & 6 & 42 & 66 & 86 & 159 & & 196 & & 45 & & $\Sigma 600$ \\
\hline & & 13,2 & 96,6 & 158,4 & 215 & 413,4 & & 548,8 & & 135 & & $X=2,63$ \\
\hline
\end{tabular}




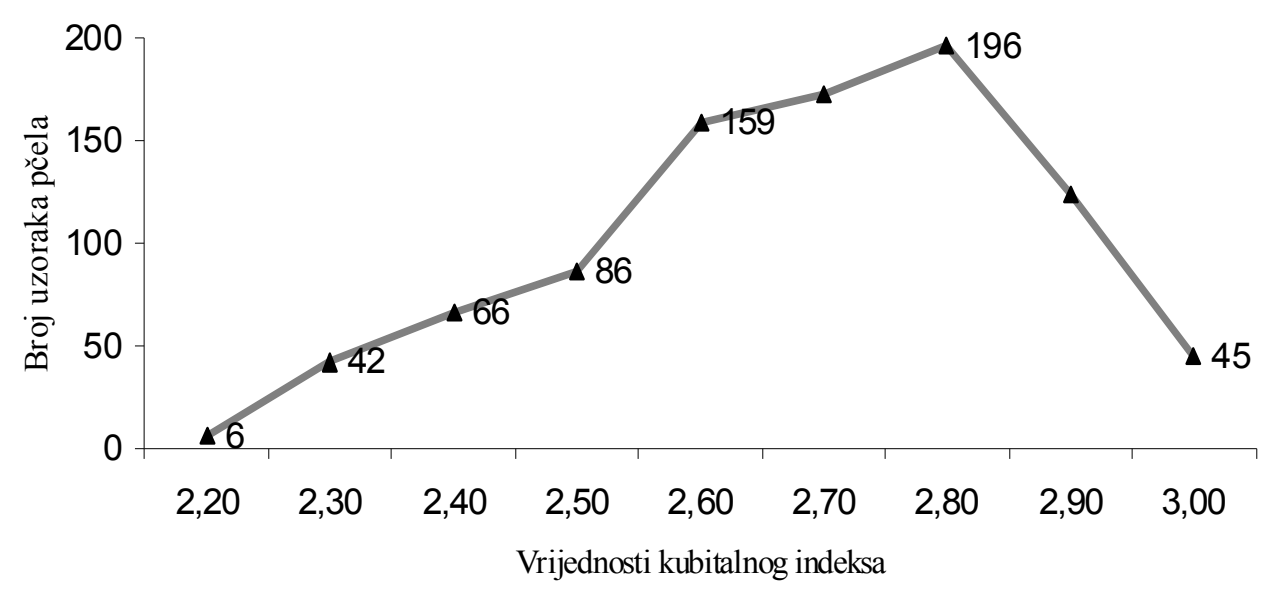

Graf.1. Grafički prikaz vrijednosti dužine kubitalnog indeksa analiziranih 600 jedinki pčela medarica sa područja Unsko-sanskog kantona

(Graf. 1. Graphical lookup of the length values of cubital index analysed 600 honey bees from Una-Sana Canton)

\section{- Intervju sa vlasnicima pčelinjaka}

Rezultati intervjua sa vlasnicima pčelinjaka pokazuju da se podudaraju karakteristike ponašanja pčela kao i biološke karakteristike, i to:

$>$ kod svih pčelara pčelinja društva imaju brz proljetni razvoj;

$>$ sva društva dobro zimuju sa srednjom jačinom pčelinje zajednice;

$>$ sa smanjenjem količine paše mijenja se količina legla i broj pčela $u$ košnicama, te dolazi do određenog poremećaja u njihovom radu;

$>$ kod svih pčelara, pčelinja društva imaju izražen nagon za rojenje, pogotovo ako se ekološki uvjeti poremete (nagli prestanak paše i sl.);

$>$ uglavnom kod svih pčelara pčele su mirne na saću i dozvoljavaju rad;

$>$ kod većine pčelara, pčele nisu sklone grabežu (otimanju tuđeg meda), osim u izuzetnim prilikama (bespašni period, društvo koje ostane bez matice);

$>$ propolis u normalnim uvjetima lijepe srednjim intenzitetom;

$>$ imaju dobro razvijen osjećaj orijentacije (manje se zalijeću u tuđe košnice) i odlaze i na veće udaljenosti radi iskorištavanja paše;

$\mathrm{Na}$ osnovu svih intervjua sa pčelarima na Unsko-sanskom kantonu o praćenju ponašanja pčela tokom sezone te o biološkim karakteristikama društava, izvodi se zaključak da pčele analiziranih društava pripadaju sivoj pčeli Apis mellifera carnica $\mathrm{P}$. 


\section{DISKUSIJA - Discussion}

Rezimirajući rezultate analize nekih morfometrijskih parametara pčele medarice u pčelinjacima (šest) na području Unsko-sanskog kantona dolazimo do činjenica da se sve izmjerene vrijednosti uklapaju u osobine svojstvene kranjskoj rasi Apis mellifera carnica P. prema vrijednostima koje je odredio Ruttner, 1988 (DOMINIKOVIĆ I SUR., 1997). Pojedinačno za svaki parametar je značajno manje odstupanje od dozvoljenih vrijednosti, a posebno se to odnosi na kubitalni indeks (CI). Grafički prikaz ukazuje na manje homogen materijal koji donekle govori o različitom porijeklu tzv. nasadnog materijala. Analizom je utvrđeno da mirnoća pčela nema nikakav utjecaj na veličinu kubitalnog indeksa, dok na agresivnost ima negativan učinak (POKLUKAR, KeZIĆ, PECHHACKER, 1994). S druge strane, povezanost između porijekla matica i okoline inducirala je signifikantno različite vrijednosti kubitalnog indeksa na različitim lokacijama kod jednakog porijekla matica (POKLUKAR, KEZIĆ, PECHHACKER, 1994). U ovim istraživanjima, za matice se zna da su različitog porijekla, a uvjeti u kojima se nalaze pčelinjaci donekle su uravnoteženi, te su i vrijednosti kubitalnog indeksa $u$ istoj ravnoteži. Ostali parametri značajni za određivanje pasmine ili rase medonosne pčele izmjereni kod 300 jedinki radilica $u$ pčelinjacima Unsko-sanskog kantona pokazuju da se sve vrijednosti poklapaju sa osobinama sive (kranjske) pčele Apis mellifera carnica P. Komparirajući dobivene rezultate sa sličnim podacima o pčeli medarici sa pčelinjaka Sarajevskog kantona (POTURAK, 2000), može se uvjetno naglasiti veća uniformnost analiziranih parametara koji su, iako donekle variraju, karakteristični za sivu (kranjsku) pčelu. Nijedan analiziran parametar nije na granici dozvoljenih vrijednosti. Podaci dobiveni na osnovu intervjua sa vlasnicima ukazuju na samoinicijativno unošenje matica koje nije kontrolisalo stručno lice što, donekle, pridonosi nehomogenosti genskog materijala pčelinjaka. Pored toga, riječ je o društvima čije pčele u košnici imaju prirodan nagon ka rojenju koji je veoma izražen. S obzirom na osnovne geoklimatske karakteristike prostora Bosne i Hercegovine i zastupljenost velikog broja medonosnih biljaka u flori, pčelarstvo predstavlja jednu od perspektivnih grana privrede. S druge strane, da bi se ublažilo miješanje matica u pčelinjacima, a na taj način spriječila pojava agresivnosti ili čak povećanje mortaliteta u društvima pčela, neophodno je uspostavljanje adekvatnih institucija i edukacija pčelara. Sve navedene neophodno je u cilju povećanja produktivnosti pčelinjih proizvoda, a s druge strane, sprečavanja pojava zaraznih bolesti koje su zastupljene na području Evrope

\section{ZAKLJUČCI - Conclusions}

U odnosu na postavljenu hipotezu i osnovne ciljeve i zadatke, a na osnovu dobivenih rezultata mjerenja nekih morfometrijskih parametara mogu se izvesti slijedeći zaključci: 
$\checkmark$ izračunate vrijednosti morfometrijskih parametara pčele medarice iz šest pčelinjaka Unsko-sanskog kantona su u granicama za sivu ili kranjsku pčelu Apis mellifera carnica $\mathrm{P}$.

$\checkmark$ uporedbom rezultata mjerenja u različitim pčelinjacima značajno je naglasiti da kod svih društava vrijednosti kubitalnog indeksa pokazuju nehomogen sastav, što je rezultat različitog porijekla matica;

$\checkmark$ vrijednosti dužine rilice variraju od 6,30 do $7,0 \mathrm{~mm}$; kubitalni indeks je sa srednjom vrijednosti 2,63;

$\checkmark$ na osnovu dobivenih vrijednosti mjerenja odabranih parametara, pčela medarica ima u potpunosti odlike sive ili kranjske pčele $A$. m. carnica P.;

$\checkmark$ na osnovu vrijednosti kubitalnog indeksa (od 2,20 do 3,0) i izgleda grafikona možemo uvjetno zaključivati o nehomogenom genetskom materijalu, a prisutan je i izražen uticaj ekoloških faktora na vanjske fenotipske karaktere;

$\checkmark$ rezultati mjerenja nekih morfometrijskih parametara pčele medarice iz pčelinjaka u Sarajevskom kantonu pokazuju veća odstupanja od dozvoljenih vrijednosti za rasu kranjske pčele;

$\checkmark$ područje Unsko-sanskog kantona prostorno i vegetacijski pruža optimalne uvjete za razvoj kontrolisanog i zakonski regulisanog uzgoja pčela u cilju razvoja pčelarstva na području Bosne i Hercegovine.

\section{LITERATURA - References}

1. Cybis Electronik \& Data AB. (2004): Austrian scientist Friedrich Ruttner he also developed a method for classifying bees by using the cubital index... 1 to above 3 , Apis mellifera mellifera having the lowest value and... $\mathrm{http} / / \mathrm{www} . c y b i s . s e /$ alltxt/bees/bees.htm

1. Ćerimagić, H., Savić, R. (1991): Pčelarstvo. 7. dopunjeno i prerađeno izd. Zadrugar, Sarajevo.

2. DogelJ, V. A. (1961): Zoologija beskičmenjaka. Naučna knjiga, Beograd.

3. Dominiković, Z., Brence-Lazarus, T., Bubalo, D., Dražić, M., Kezić, N. (1997): Program gojidbenog stvaranja pčela u R Hrvatskoj. Hrvatski stočarski selekcioni centar, Zagreb.

4. Koning, R.E. (1994): "Honeybee Biology". Plant Physiology Website. Http://plantphys.info/plants-human/bees/bees.html

5. LAKUŠIĆ, R., PAVlović, D., ABADžIĆ, S., GRGIĆ, P.: Prodromus biljnih zajednica Bosne i Hercegovine. Biološki institut Univerziteta u Sarajevu, Sarajevo, 1978.

6. MATONIČKIN, I.: Beskralježnjaci: biologija viših avertebrata. 2. izd. Školska knjiga, Zagreb.,1991, 294-300

7. MatoničKIn, I., HabdiJA, I., Durbešı́, P., ERben, B., PRIMC, B. (1986): Praktikum iz avertebrata. Sveučilišna naklada Liber, Zagreb, Udžbenik Sveučilišta u Zagrebu. 
8. MATONIČKIN, I.,: Životinje: velika ilustrovana enciklopedija. Mozaik knjiga, Zagreb, 2001, 573-574

9. PECHENIK, J. A. (1996): Biology of the Invertebrates. WCB McGraw-Hill, Boston etc., 404-405

10. PotURAK, S. (2000): Biotaksonomske odlike medonosne pčele na području Kantona Sarajevo: diplomski rad. Prirodno-matematički fakultet, Sarajevo.

11. Poklukar, J., Kezić, N., PeChHacker, H. (1994): Cubital index and behavioural characteristic of the honey bee Apis mellifera carnica. Apidologie, 5 (25): 194495.

12. Poklukar, J., Kezić, N., Pechhacker, H. (1995): Cubital index of honeybee workers (Apis mellifera carnica) of three different origins on three different locations. Apidologie, 21-23.

13. StANImIROVIĆ, Z., Soldatović, B., VučINIĆ, M. (2000): Biologija pčela. Medicinska knjiga, Beograd.

\section{SAŽETAK - Summary}

Due to its significance in the overall state economy based on the production of honey, wax and propolis in the European region, the honey bee Apis mellifera L. is represented in four breeds: dark Duch-German bee Apis mellifera mellifera Linne 1758, Caucasian honey-bearing bee A.m.caucasica Gorb., Carniolan bee, A.m.carnica Pollman 1879, and Italian bee A.m.ligustrica Spinola 1806. Based on the current data (Ćerimagić, 1990, Poturak, 2000) the honey bearing Carniolan bee, A.m.carnica is being raised in the apiaries of Bosnia and Herzegovina. The paper presents the results of some morphometric measurements (the length of proboscis and cubital index) that were performed at five apiaries in the area of Una-Sana Canton that were relevant for establishing the breed of the honey bearing bee. The measurement of the length of proboscis was performed at 300 bee units and have indicated that this parameter varies from $6,30 \mathrm{~mm}$ to $7,00 \mathrm{~mm}$, with the mean value of $6,56 \mathrm{~mm}$. The calculated values are typical for the Carniolan bee, A.m.carnica. The value of cubital index varied between 2,20 and $3,00 \mathrm{~mm}$, with the mean value of 2,63, which is typical for the honey bearing Carniolan bee, A.m.carnica. Based on the data obtained from the owners of the apiaries the analyzed entities partially comprised the no-homogenous genetic system due to diverse origin of the queen bees. The area of the Una Sana Canton otherwise offers an optimal environment for the development of apiculture which will be properly regulated, and which will considerably contribute to prevention of spreading of some contagious diseases typical for European areas. 